\title{
Attitude of Antenatal Mothers toward Cesarean Section Delivery
}

\author{
Anjumol Varghese, Linu Philip, Ribcy Annie Monachan, C. Binsha Pappachan, Loma Marjorie Pinto \\ Department of Mental Health Nursing, Father Muller College of Nursing, Mangalore, Karnataka, India
}

\section{Abstract}

Background: Globally, the rate of cesarean section (CS) delivery has been increasing among women. The perceptions surrounding CS delivery may have a significant role in the decision-making process which influenced by multiple complex factors such as cultural values, beliefs, and anticipations of the birth, possible traumatic events in life, available social support, and personal sense of control are only a few.

Aim: This study aims to compare the attitude toward CS delivery between primigravid women and multigravid women with and without previous history of CS delivery and also to find the association of attitude of antenatal mothers with their selected demographic variables.

Methodology: The descriptive study approach has been used in view of accomplishing the main objectives of the study. The tools consist of demographic profile along with structured attitude questionnaire. The subject consisted of 100 antenatal mothers and was selected by purposive sampling technique. Data were analyzed using descriptive and inferential statistics.

Results: The attitude assessed using attitude scale showed that majority of antenatal mothers $(66 \%)$ had favorable attitude toward CS. There was no significant relationship between the attitude of primigravid and multigravid mothers. There was no significant association found between the attitude of antenatal mothers with their selected demographic variables such as age, religion, type of family, education, income per month, residence, parity, and mode of delivery.

Conclusion: Although the findings revealed that most pregnant women prefer CS delivery, it was found that pregnant women need more guidance by midwives and obstetricians.

Keywords: Antenatal mothers, attitude, CS delivery

\section{INTRODUCTION}

Cesarean section (CS), also commonly known as C-section and, is a surgical procedure, in which one or more incisions are made through a mother's abdomen and uterus to deliver one or more babies. ${ }^{[1]}$ A CS is often performed when a vaginal delivery would put the baby's or mother's life or health at risk. Some are also performed on request without a medical reason to do so. The WHO recommends that they should be done based only on medical need. ${ }^{[2]}$

Globally, the rate of CS has been increasing. The safety of the procedure has resulted in some women requesting

\begin{tabular}{|l|}
\hline \multicolumn{1}{|c|}{ Access this article online } \\
\hline Website: http://innovationalpublishers.com/Journal/ijnmi \\
\hline ISSN No: $2656-4656$ \\
DOI: $10.31690 /$ ijnmi/52 \\
\hline
\end{tabular}

it in the absence of any medical indication, particularly in the developed countries. ${ }^{[3]}$ A number of women have good knowledge regarding $\mathrm{CS}$ is preferable to vaginal delivery as pain in vaginal delivery is usually unpleasant. Although recent studies have shown that the risk of planned CS and planned vaginal delivery in the short term is low and similar, in subsequent pregnancies, the risk will be higher in a mother who has had a previous CS. ${ }^{[4]}$

It is difficult to pinpoint an exact cause for the rising rates of CS. Medical, institutional, legal, psychological, and sociodemographic factors play a contributing role. ${ }^{[5]}$ India is also not excluded from this trend. At the all India level, the rate has increased from $2.9 \%$ of the childbirth in 1992-1993 to 7.1 in agreeing for cesarean delivery for medical and even for non-medical reason without knowing true risk and benefits of the procedure. ${ }^{[6]}$

One of the main goals of every medical team, dealing with childbirth, is performing a safe delivery. CS are one of the

This is an open-access journal, and articles are distributed under the terms of the Creative Commons Attribution Noncommercial Share Alike 4.0 License, which allows others to remix, tweak, and build upon the work non-commercially, as long as appropriate credit is given and the new creations are licensed under the identical terms 
most frequently performed operations in women. One of the most dramatic features of modern obstetrics is the relentless increase in the cesarean rate. This escalating cesarean rate is a major public health problem because CS increases the health risk for mothers and babies as well as the cost of health care compared with normal deliveries. ${ }^{[7]}$ Hence, the study was conducted to compare the attitude toward CS delivery between primigravid women and multigravid women with and without previous history of CS delivery and also to find the association of attitude of antenatal mothers with their selected demographic variables.

\section{Methodology}

One hundred antenatal mothers, who attended the inpatient and outpatient departments, were enrolled in this study using systematic random sampling at obstetrics and gynecology wards and outpatient department (OPD) in a selected hospital at Mangaluru from June 27, 2016, to July 2, 2016. The antenatal mothers were included if (a) antenatal mothers who are available in inpatient/outpatient facility at the setting, (b) both primi- and multi-gravid antenatal mothers irrespective of the previous history of CS, and (c) mothers who know the languages of Kannada, Malayalam, and English. The mothers were excluded if (a) mothers in labor process is initiated, (b) mothers those who are not willing to participate, and (c) mothers who are not available at the time of data collection.

\section{Study tool}

The study tool consisted of two sections. Section I contained 9 items related to demographic profile of the mothers such as age, religion, type of family, level of education, occupation, income, residence, and parity. Section II was an attitude scale. The researcher prepared the rating scale consisted of 21 items to assess the attitude of antenatal mothers toward CS. The items were closed-ended questions with five alternative responses to each. Each item had only one correct response. Correct response carries 5 marks for high level of attitude and 1 mark for low level of attitude. The maximum total score was 105 and minimum total score was 21 .

\section{Methods}

The investigators visited the obstetric and gynecological ward, OPD and collected data from the participant. After introducing the purpose of the study, confidentiality was assured and written consent was obtained from the participants indicating their willingness to participate in the study. The tool was administered to the participants with explanation. After data collection, the investigator thanked the respondents for their participation in the study.

\section{Ethical consideration}

Ethical clearance was obtained from the Institution Ethics Committee. The pilot study was conducted in the obstetric wards.

\section{Data analysis}

The data were presented as frequency and percentages.

\section{RESULTS}

\section{Demographic characteristics}

Table 1 shows demographic characteristics of the study subjects. About $52 \%$ of the mothers aged between 18 and 25 years followed by $33 \%$ of mothers aged 26-30 years. Only $4 \%$ of mothers aged $>34$ years. About $55 \%$ of the mothers were Muslims and $23 \%$ of the mothers were Christian. About $54 \%$ of the study subjects were living in nuclear family and $56 \%$ belonged to rural area. About $41 \%$ of them were graduates while only $1 \%$ was illiterate. About $77 \%$ of subjects were housewives. Only $15 \%$ of mothers have family income of more than Rs. 15,000/-. About $47 \%$ of the mothers were primigravid women [Figure 1] while $60 \%$ of mothers underwent CS delivery [Figure 2].

\section{Attitude of antenatal mothers toward cesarean section}

The data presented in Figure 3 show that most of the antenatal mothers $(66 \%)$ are had favorable attitude toward CS. Remaining 34\% had unfavorable attitude toward CS.

The results of factors contributing toward the attitude show that psychological factors are the main contributing factors (mean $32.65 \pm 5.9)$ and physical factors $(19.87 \pm 3.4)$.

Table 1: Demographic characteristics

\begin{tabular}{|c|c|c|}
\hline Variables & Frequency & Percentage \\
\hline \multicolumn{3}{|l|}{ Age in years } \\
\hline $18-25$ & 52 & 52 \\
\hline $26-30$ & 33 & 33 \\
\hline $31-35$ & 11 & 11 \\
\hline$>36$ & 4 & 4 \\
\hline \multicolumn{3}{|l|}{ Religion } \\
\hline Hindu & 22 & 22 \\
\hline Muslim & 55 & 55 \\
\hline Christian & 23 & 23 \\
\hline \multicolumn{3}{|l|}{ Type of family } \\
\hline Nuclear & 54 & 54 \\
\hline Joint family & 46 & 46 \\
\hline \multicolumn{3}{|l|}{ Level of education } \\
\hline Illiterate & 1 & 1 \\
\hline Primary education & 7 & 7 \\
\hline Secondary education & 44 & 44 \\
\hline Graduate & 41 & 41 \\
\hline Postgraduate & 7 & 7 \\
\hline \multicolumn{3}{|l|}{ Occupation } \\
\hline Homemaker & 77 & 77 \\
\hline Self-employed/business & 1 & 1 \\
\hline Professional & 17 & 17 \\
\hline Others & 5 & 5 \\
\hline \multicolumn{3}{|l|}{ Monthly income } \\
\hline$<5000 /-$ & 26 & 26 \\
\hline $5001-10,000 /-$ & 38 & 38 \\
\hline $10,001-15,000$ & 21 & 21 \\
\hline 15,001 and above & 15 & 15 \\
\hline \multicolumn{3}{|l|}{ Residence } \\
\hline Rural & 56 & 56 \\
\hline Urban & 44 & 44 \\
\hline \multicolumn{3}{|l|}{ Parity } \\
\hline Primigravid & 47 & 47 \\
\hline Multigravid & 53 & 53 \\
\hline \multicolumn{3}{|l|}{ Mode of delivery } \\
\hline Vaginal delivery & 32 & 60.37 \\
\hline Cesarean delivery & 21 & 39.62 \\
\hline
\end{tabular}

Data expressed as frequency and percentages 
Socioeconomic factors were the other contributing factors $(8.96 \pm 2.12)$ and spiritual factors were the least contributing factors $(5.28 \pm 1.44)$.

Comparison of the attitude of primigravid women and multigravid women with and without previous history of CS delivery revealed that there was no significant difference between the attitude of women toward CS $(t=0.608)$. Association between the attitudes toward CS and selected demographic variables were tried to establish, and the results revealed that there was no significant association found between the attitudes of antenatal mothers with their selected demographic variables $(P>0.05)$.

\section{Discussion}

The present study shows that among the subjects selected for the study, highest percentage (52\%) of antenatal mothers belongs to the age group of 18-25 years. Majority of the antenatal mothers (55\%) belongs to Islam religion, Christian $23 \%$, and Hindu $22 \%$. Most of the antenatal mothers (54\%) belong to nuclear family and $46 \%$ of antenatal mothers belonged to joint family. Most of the subjects (44\%) had secondary education as their basic education and $41 \%$ of subjects are graduates. Highest percentage (77\%) of antenatal mothers is homemakers and $17 \%$ were professional workers and $6 \%$ are others. Majority of the antenatal mothers $(53 \%)$ are multigravid and $(47 \%)$ are primigravid. Majority of the multigravid mothers underwent vaginal delivery $(60 \%)$.

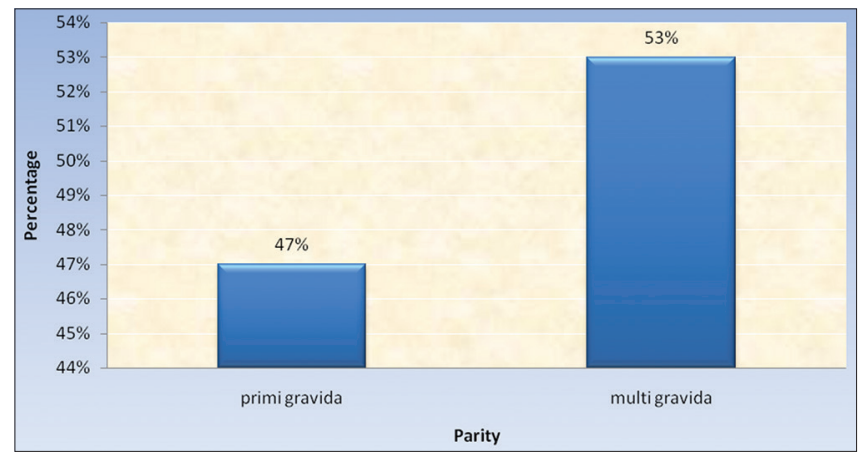

Figure 1: Distribution of subjects according to their parity
The study findings revealed that most of the antenatal mothers $(66 \%)$ are had favorable attitude toward CS. Remaining 34\% had unfavorable attitude toward CS. A descriptive study was conducted at the University of Benin Teaching Hospital in Nigeria to determine the perceptions and attitudes toward CS. From the study, it is found that the women had good knowledge and favorable attitude toward CS; however, only $6.1 \%$ were willing to accept CS as a method of delivery, while $81 \%$ would accept CS if needed to save their lives and that of their babies. Up to $12.1 \%$ of women would not accept CS under any circumstances. Logistic regression showed that women's low level of education, and past successful vaginal and instrumental deliveries, was most likely to be associated with women's non-acceptance of indicated CS. ${ }^{[8]}$

A cross-sectional descriptive study was conducted among Nepalese women with an objective to evaluate the knowledge and attitude toward mode of delivery and cesarean on demand. Two hundred pregnant women after 37 completed weeks of gestation were recruited randomly and interviewed, and their answers were analyzed. Vaginal delivery was the preferred mode in $93 \%$ and $7 \%$ preferred cesarean delivery. Only $35 \%$ of the interviewed women believed that women should have the right to demand a CS. ${ }^{[9]}$

There were studies which showed different findings from Hong Kong Chinese women aged 18-45, who were pregnant or had given birth within the past 3 years which were recruited. A total of 319 women were recruited, of whom 73 preferred to have a CS. The results showed that women preferred CS delivery because they were concerned about being pregnant at an advanced age, were worried about labor pain and perineum tearing, wanted to have a better plan for maternity leave, had chosen an auspicious date to deliver, and perceived that CS delivery is a more convenient way to deliver. ${ }^{[10]}$

The present study revealed that there is no difference in the attitude of primigravid mothers and multigravid mothers toward the CS. However, there was a study conducted at a selected hospital in Coimbatore. The study was designed to assess the knowledge and attitude of antenatal mothers toward $\mathrm{CS}$ and normal vaginal delivery. The data were collected from

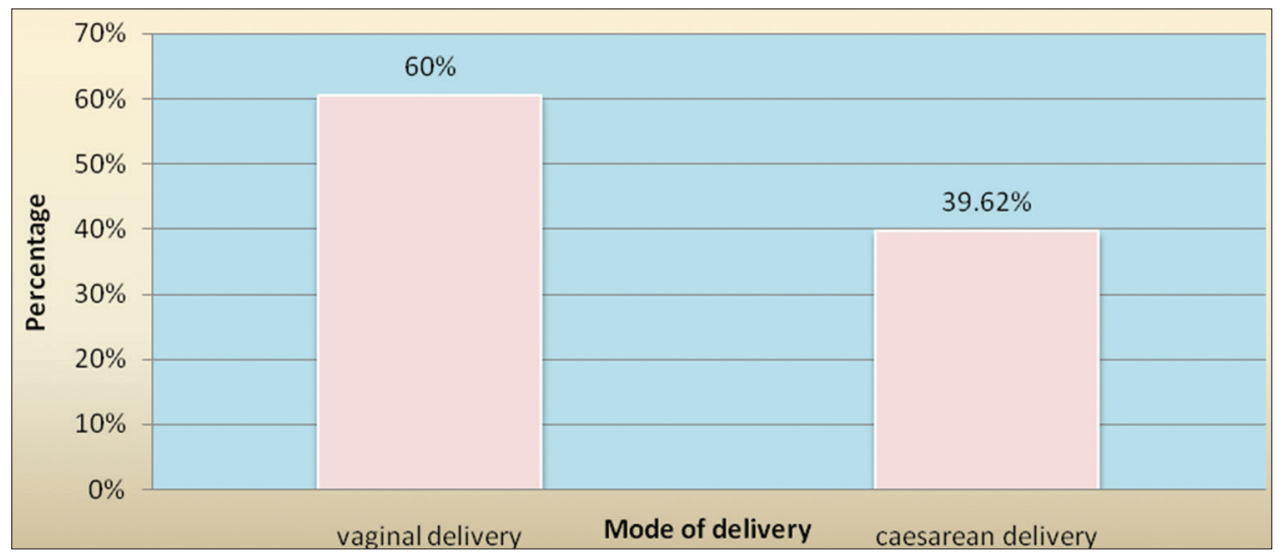

Figure 2: Distribution of subjects according to the mode of delivery in multigravid mothers 


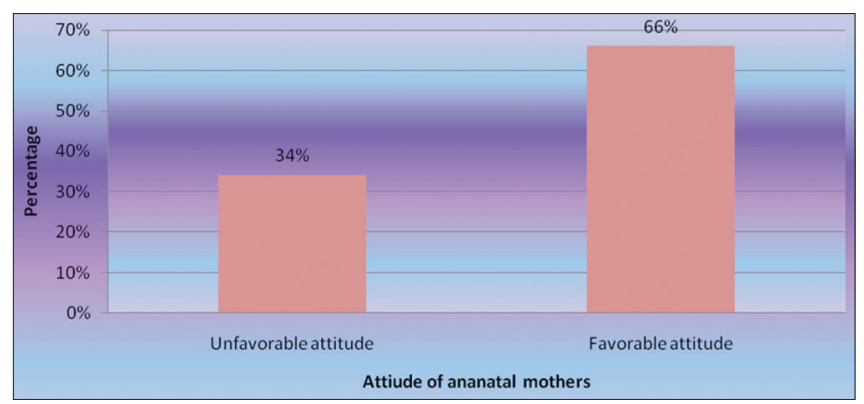

Figure 3: The distribution of antenatal mothers according to their attitude score toward cesarean section

100 samples using convenient sampling technique through survey method. Multigravid mothers had positive attitude and primi mothers had negative attitude toward CS. ${ }^{[1]}$

\section{Conclusion}

The main purpose of the study was to assess the attitude of the antenatal mothers toward CS. The rising cesarean birth rate in developing countries is an important issue; to decline this trend, health professional should provide the true information to the pregnant women and their partners about the modes of delivery, their indications, advantages, and adverse consequences during antenatal period. This knowledge will change their outlook and make them a better judge while choosing their preferences.

\section{ACKNOWLEDGMENT}

The authors would like to thank all respondents who are involved in this research study. All the authors are wholeheartedly thankful to the people who are directly or indirectly responsible for the completion of the work, especially our institution Father Muller College of Nursing and Father Muller Medical College Hospital, Mangaluru, for allowing us to conduct this study.

\section{REFERENCES}

1. Todman D. A history of caesarean section: From ancient world to the modern era. Aust N Z J Obstet Gynaecol 2007;47:357-61.

2. World Health Organization. Medical Device Regulations: Global Overview and Guiding Principles. Geneva: World Health Organization; 2003.

3. Betrán AP, Ye J, Moller AB, Zhang J, Gülmezoglu AM, Torloni MR, et al. The increasing trend in caesarean section rates: Global, regional and national estimates: 1990-2014. PLoS One 2016;11:e0148343.

4. Keag OE, Norman JE, Stock SJ. Long-term risks and benefits associated with cesarean delivery for mother, baby, and subsequent pregnancies: Systematic review and meta-analysis. PLoS Med 2018;15:e1002494.

5. Bayou YT, Mashalla YJ, Thupayagale-Tshweneagae G. Patterns of caesarean-section delivery in Addis Ababa, Ethiopia. Afr J Prim Health Care Fam Med 2016;8:e1-6.

6. Singh P, Hashmi G, Swain PK. High prevalence of cesarean section births in private sector health facilities analysis of district level household survey-4 (DLHS-4) of India. BMC Public Health 2018;18:613.

7. Milcent C, Zbiri S. Prenatal care and socioeconomic status: Effect on cesarean delivery. Health Econ Rev 2018;8:7.

8. Ashimi A, Amole T, Aliyu L. Knowledge and attitude of pregnant women to caesarean section in a semi-urban community in Northwest Nigeria. J West Afr Coll Surg 2013;3:46-61.

9. Joshi A, Thapa M, Panta OB. Maternal attitude and knowledge towards modes of delivery. J Nepal Health Res Counc 2018;16:209-14.

10. Loke AY, Davies L, Li SF. Factors influencing the decision that women make on their mode of delivery: The health belief model. BMC Health Serv Res 2015;15:274.

11. Kavitha V. Assessment of knowledge and attitude of antenatal mothers towards caesarean section and normal vaginal delivery at selected hospital, Coimbatore. Asian J Nurs Educ Res 2013;3:8.

How to cite this article: Varghese A, Philip L, Monachan RA, Pappachan CB, Pinto LM. Attitude of Antenatal Mothers toward Cesarean Section Delivery. Int J Nurs Med Invest. 2019;4(3):58-61 